\title{
Abundance estimate and seasonal patterns of grey seal (Halichoerus grypus) occurrence in Brittany, France, as assessed by photo-identification and capture-mark-recapture
}

\author{
Maureen Gerondeau**, Christophe Barbraud ${ }^{\dagger}$, Vincent Ridoux* and Cécile Vincent* \\ *Centre de Recherches sur les Ecosystèmes Littoraux Anthropisés (CRELA), UMR 6217, Université de La Rochelle, Avenue \\ Michel Crépeau, 17042 La Rochelle cedex, France. 'Centre d'Etudes Biologiques de Chizé (CEBC), UPR CNRS 1934, Villiers- \\ en-Bois, 79360 Beauvoir sur Niort, France. *Corresponding author, e-mail: maureengerondeau@yahoo.fr
}

\begin{abstract}
It has been suggested that the large grey seal colonies around the British Isles form local populations within a metapopulation, and that seal movements outside the breeding season lead to considerable overlap between individual home ranges. Individual behaviour and population dynamics of small peripheral colonies may also play a role in the metapopulation. We studied the French grey seal colony of the Molène archipelago, at the southern-most limit of the species' range. We analysed photo-identification data with capture-mark-recapture techniques in order to estimate the total seasonal abundance of grey seals in the archipelago and to quantify the seasonal rates of occurrence or movements of male and female seals. We found that between 58 (95\% confidence interval: 48-71) and 98 (95\% CI: 75-175) individuals hauled out in the archipelago during the summers of 1999 and 2000. The use of multistate models allowed the assessment of seasonal site fidelity and indicated that it varied between key periods of the annual cycle, particularly for females. Males showed a constant fidelity rate of $56 \%$ from one season to another. Hence, even though they showed high inter-annual site fidelity, they did not seem to have a preferred season for using the archipelago. On the contrary, female grey seals showed the highest site fidelity between moult and summer (around 80\%), and the lowest fidelity between summer and the breeding period (34-43\%). Thus, females seem to use the Molène archipelago preferentially in summer and leave the site before the breeding season, which explains the very low local pup production. Philopatry may explain this pre-breeding emigration, and we suggest that most grey seals observed in the Molène archipelago were born and breed in other local breeding populations, probably the south-western British Isles.
\end{abstract}

\section{INTRODUCTION}

The north-east Atlantic grey seal Halichoerus grypus occurs in a vast area stretching from the Kola Peninsula in northern Russia to France with a large majority of the population in Great Britain where around 113,300 individuals were estimated in 2003 (SMRU, 2004). This represents about 40\% of the world population. Allen et al. (1995) showed genetic differentiation between distinct UK breeding colonies and it has been suggested that these colonies form local populations of a metapopulation (Gaggiotti et al., 2002; Matthiopoulos et al., 2005). On the other hand, grey seal movements around the UK have been documented during the last two decades thanks to telemetry (e.g. Thompson et al., 1991; McConnell et al., 1999) and the considerable overlap between foraging ranges of seals tagged in different colonies led the authors to suggest that these seals belong to a single ecological management unit (Hammond et al., 1993; Thompson et al., 1996). Individual grey seal movements have also been described from smaller peripheral groups (e.g. Kiely et al., 2000; Vincent et al., 2005; Härkönen et al., in press). One of the smallest and most isolated of these peripheral groups is situated in Brittany, France, where grey seals occur at the southern-most limit of the species' range. Abundance estimates for this colony are still missing. Censuses were conducted between 1991 and 2000, and showed an increase in the relative abundance of seals at haul-out sites of $7 \%$ per year (Vincent et al., 2005), similar to that observed in Great Britain during the same period (Hiby et al., 1996). These censuses indicated seasonal variations in the relative

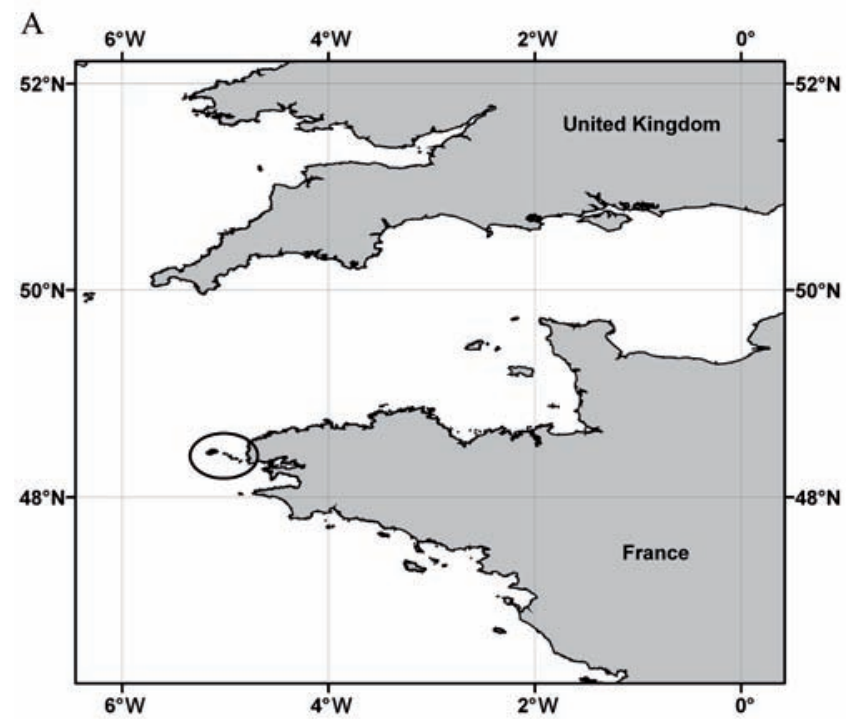

Figure 1. Location of the study site, the Molène archipelago, at the western point of Brittany, France. 
abundance and composition by sex and age of the group, and satellite tracking highlighted individual movements to other grey seal colonies in the south-western British Isles.

The aim of this paper was to estimate the total abundance of grey seals in the Molène archipelago and quantify the seasonal rates of occurrence or movements of male and female grey seals using photo-identification data and capturemark-recapture techniques. We aimed at assessing whether the Molène archipelago is used randomly or preferentially at specific periods of the year by seals. Moreover, understanding the functioning of this colony could help us to predict the trend of small peripheral populations of grey seals at the margins of the British central populations.

\section{MATERIALS AND METHODS}

\section{Data collection}

Grey seals of the Molène archipelago (48 $41^{\prime} \mathrm{N} 4^{\circ} 93^{\prime} \mathrm{W}$; Figure 1) were photo-identified during 46 sessions from March 1998 to August 2000. A session lasted between two days (the minimum time necessary to visit all potential haulout sites used by the seals in the archipelago) and three successive days of fieldwork. The surveys were conducted between two hours before low tide and low tide hour, in order to photograph as many seals as possible. Photographs were taken from a boat or from rocks using a Canon EOS 500 camera fitted with a Canon 500 mm lens and a Kenko 2X converter.

We used natural pelage markings of the individuals for their identification (Hiby \& Lovell, 1990). Grey seals display sexual dimorphism, so males and females cannot be identified using the same criteria (Hewer \& Backhouse, 1959). Females are lighter than males with distinctive and visible black spots that make individual identification easier. Males are generally darker, and can become completely black, so identification is usually made from scars or injuries when present, if no contrasting spots are visible on the fur. Pelage patterns are permanent over successive annual moults, although darkening of the black spots occurs during the first years of life of males and females (Vincent et al., 2001). We therefore did not include yearlings in the photoidentification catalogue. The head and the neck of all seals in the water were photographed from each side. When the two sides showed marks allowing safe recognition, the animal was given an ID number. Finally, successive recaptures of identified individuals were recorded with the place, date and time of photographs.

All animals were photographed in the field, and then classified in three groups according to their pelage pattern (Vincent et al., 2001). A Good pattern was assigned to individuals with well defined and easily recognizable marks. Individuals with a less well defined pattern but yet identifiable were noted as Medium and those with no identifiable marks were classified as Bad. Only seals with a Good or Medium pelage pattern were then included in the identification catalogue.

\section{Abundance estimate}

In general, the abundance of grey seal populations is estimated from the annual pup production (e.g. Hammill et al., 1998; Kiely \& Myers, 1998; SMRU, 2004). In the present case, this technique could not be used because the pup production of the colony in Molène is too low (Vincent, 2001). Besides, estimating seasonal abundance was one of the main aims of this work. Instead, photo-identification and capture-mark-recapture techniques were used.

In order to estimate the abundance of grey seals in the Molène archipelago during different periods, models with more than two capture occasions for closed populations were used. These models were defined by Otis et al. (1978) and derived from a null model $\mathrm{M}_{0}$ based on four assumptions: (1) the population is closed; (2) the animals do not lose their marks during the experiment; (3) all the marks are noted properly and recorded on each capture occasion; and (4) all the individuals have an equal and constant capture probability on each occasion.

Based on individual recapture series, we concluded that the population could be considered as closed when four successive sessions were conducted within one month and, most importantly, within a key period of the annual cycle of the grey seal (breeding, moulting, or summer foraging periods). The assumption that individual capture probabilities are equal and constant is often not confirmed (Otis et al., 1978). This can introduce a bias in the estimates. Therefore, models allowing heterogeneity in capture probabilities have been developed. They take into account three sources of variation: time $(\mathrm{t})$, individual heterogeneity $(\mathrm{h})$, and individual behaviour (b). Hence, eight models $\left(\mathrm{M}_{0}, \mathrm{M}_{\mathrm{t}}, \mathrm{M}_{\mathrm{h}}, \mathrm{M}_{\mathrm{b}}, \mathrm{M}_{\mathrm{th}}\right.$, $\mathrm{M}_{\mathrm{tb}}, \mathrm{M}_{\mathrm{hb}}, \mathrm{M}_{\mathrm{tbh}}$ ) can be used to estimate the abundance of a group of individuals. The program CAPTURE (Otis et al., 1978; White et al., 1982) helps the user in choosing the most appropriate model. Sources of variation of capture probabilities were first studied in order to select models consistent with the conditions of observation and the biology of the species. Among the three potential sources of variation, only time and individual heterogeneity were retained. Seals were not physically captured and photographs were taken sufficiently far from the animals; there was little chance to elicit a behavioural response to the photographic capture that would modify subsequent capture probability. Thus, the models tested were $\mathrm{M}_{\mathrm{h}}, \mathrm{M}_{\mathrm{t}}$, and $\mathrm{M}_{\mathrm{th}}$.

For model $\mathrm{M}_{\text {th }}$, Chao et al. (1992) recommend looking at the coefficient of variation of the individual capture probabilities $\mathrm{CV}\left(\mathrm{p}_{\mathrm{i}}\right)$ and at the sample coverage $\hat{\mathrm{C}}$. If $\mathrm{CV}\left(\mathrm{p}_{\mathrm{i}}\right)$ is smaller than 0.4 and the sample coverage is larger than $50 \%$, it is preferable to use the estimator of Darroch (1958). But if $\mathrm{CV}\left(\mathrm{p}_{\mathrm{i}}\right)$ is larger than 0.4 and the sample coverage is larger than $50 \%$, Chao et al. (1992) recommend using their estimator $\mathrm{M}_{\text {th }}$. In the case of a small sample coverage, the 'jackknife' estimator of the $\mathrm{M}_{\mathrm{h}}$ model is the most appropriate.

In capture-mark-recapture analyses, the heterogeneity of capture probabilities should be reduced to a minimum (Hammond, 1986). In order to test the influence of pelage pattern quality (i.e. quality of marks) on abundance estimates, two series of analyses were conducted: one based on recaptures of individuals with Good patterns only, and one with seals showing either Good or Medium pelage pattern qualities. Since only the animals with a Good or Medium pelage pattern were taken into account for the analysis, only the abundance of identifiable individuals $(\hat{\mathrm{N}})$ was estimated. 
Table 1. Multistate models with first-order Markovian transition estimating all parameters with an observable state $(O)$ and an unobservable state $(U)$.

\begin{tabular}{ccc}
\hline Transition & Survival & Capture \\
\hline$\psi_{\mathrm{t}}^{\mathrm{OU}} \neq \psi_{\mathrm{t}}^{\mathrm{UO}}$ & $\mathrm{S}_{\mathrm{t}}^{\mathrm{O}}=\mathrm{S}_{\mathrm{t}}^{\mathrm{U}}$ & $\mathrm{p}$. \\
$\mathrm{S}^{\mathrm{O}}=\mathrm{S}^{\mathrm{U}}$ & $\mathrm{p}$. \\
$\psi^{\mathrm{OU}} \neq \psi^{\mathrm{UO}}$ & $\mathrm{S}_{\mathrm{t}}^{\mathrm{O}}=\mathrm{S}_{\mathrm{t}}^{\mathrm{U}}$ & $\mathrm{p}_{\mathrm{t}}$ \\
& $\mathrm{S}_{\mathrm{t}}^{\mathrm{O}}=\mathrm{S}_{\mathrm{t}}^{\mathrm{U}}$ & $\mathrm{p}$. \\
& $\mathrm{S}^{\mathrm{O}}=\mathrm{S}^{\mathrm{U}}$ & $\mathrm{p}_{\mathrm{t}}$ \\
& $\mathrm{S}^{\mathrm{O}}=\mathrm{S}^{\mathrm{U}}$ & $\mathrm{p}$. \\
\hline
\end{tabular}

't' indicates a temporal variation and '.' a constant parameter.

In order to assess the total population size $\left(\hat{\mathrm{N}}^{\prime}\right)$, the abundance estimate of identifiable individuals has to be corrected by a correction factor $\hat{\mathrm{c}}$ which is the ratio between the total number of individuals present on the site (Good, Medium and Bad pelage patterns) and the number of identifiable individuals (Good and Medium pelage patterns):

$\hat{N}^{\prime}=\hat{N} \cdot \hat{c}$

This correction factor corresponded to the proportion of each pattern among all individuals observed in the archipelago. These proportions were calculated from the percentages of Good, Medium and Bad patterns assigned among different age- and sex-classes given in Vincent et al. (2001). The limits of the 95\% confidence interval were also corrected by this factor $\hat{\mathrm{c}}$.

\section{Assessment of seasonal fidelity}

Seasonal occurrence of grey seals in the Molène archipelago was also modelled from capture-markrecapture $(\mathrm{CMR})$ data. Individual recaptures were pooled into three key periods of the biological cycle of the grey seal, over 24 months: summer 1998 (July-August), breeding 1998 (October-November), moult 1999 (February-March), summer 1999, breeding 1999, moult 2000 and summer 2000. This pooling ended in a capture-recapture data set with seven occasions.

We analysed male and female recaptures separately using a multistate mark-recapture model with an unobservable state (Kendall \& Nichols, 2002). Providing capture probabilities are high enough, the absence of photographic recapture of an individual during a given period can be considered as a 'real' absence. The use of both an observable state for seals present on site and an unobservable state for seals absent allows modelling of seasonal (temporary) emigration, immigration or site fidelity from one key period to the next. The following parameters were estimated: the survival probability $\mathrm{S}$ of individuals in each state, the capture probability $\mathrm{p}$ of individuals in the observable state (the capture probability of individuals in the unobservable state is set at 0 ), and the probability of transition between the two states $\Psi$. In this study, the probability that a seal in the observable state at one season is in the observable state in the following season can be considered as an estimate of seasonal site fidelity. According to Kendall \& Nichols (2002), six models with first-order Markovian transitions and statedependent survival can be tested to estimate all parameters in the case of two states with an unobservable one. These models are presented in Table 1. Moreover, we can test a model where transitions are completely random with no Markovian structure, in other words equal, when survival rates are not state specific and capture probability of the observable state almost equals 1 (Kendall \& Nichols, 2002). Seasonal fidelity was evaluated by conducting two analyses in parallel with the two most general models: the model $\mathrm{So}(\mathrm{t})=\mathrm{Su}(\mathrm{t}), \mathrm{p}(), \Psi \mathrm{ou}(\mathrm{t}) \neq \Psi \mathrm{uo}(\mathrm{t}) ;$ and the model $\mathrm{So}(\mathrm{t})=\mathrm{Su}(\mathrm{t})$, $\mathrm{p}(\mathrm{t}), \Psi \mathrm{ou}() \neq \Psi \mathrm{uo})$ (Table 1). The different parameters were then constrained.

There is no goodness-of-fit (GOF) test for multistate mark-recapture models with an unobservable state. Thus, we tested the GOF of the basic Cormack-Jolly-Seber (CJS) model, $\Phi_{t} p_{t}$ (Lebreton et al., 1992) which can be considered as a particular case of multistate models. If this model fits the data, a multistate model, which is more general, is considered to fit the data too. The GOF tests were conducted using program U-CARE (Choquet et al., 2003) in order to look for a transient or a trap-dependence effect. We used program MARK (White \& Burnham, 1999) to select the best multistate model. When conducting our analyses we checked for local minima in the deviance profile.

\section{RESULTS \\ Model selection by CAPTURE}

Estimates were made for the following periods: 30 May to 16 June 1998, 5 to 26 July 1998, 30 July to 12 August 1998, 18 May to 18 June 1999, 16 June to 18 July 1999, 2 to 30 July 1999, 2 to 30 August 1999, 28 August to 16 September 1999, 10 January to 23 March 2000, 23 June to 1 August 2000, 5 July to 6 August 2000. The 10 January to 23 March 2000 period was longer than the others. It corresponded to the moulting period of the seals (when most individuals remain hauled-out in the same site most of the time) and was the only winter period for which enough data were available for abundance estimates.

When analyses were made only with the capture histories of individuals with a Good pelage pattern, the most frequently selected model (6 periods out of 11) was $\mathbf{M}_{\text {th }}$, i.e. the model with capture probabilities varying with time and between individuals.

When capture histories of individuals with a Good pattern and those with a Medium one were included, the frequently selected model (7 periods out of 11) was $\mathrm{M}_{h}$.

\section{Analysis of individual capture probabilities and sample coverage}

CAPTURE has reduced statistical power when used with small datasets, so the individual capture probabilities $\mathrm{CV}\left(\mathrm{p}_{\mathrm{i}}\right)$ and sample coverage $\hat{\mathrm{C}}$ for each period were analysed. 
Table 2. Modelling seasonal occurrence of males during seven periods (summer 98, breeding 98, moult 99, summer 99, breeding 99, moult 2000, summer 2000) using multistate models (o, observable state; $u$, unobservable state). The best model is shown in bold typeface.

\begin{tabular}{|c|c|c|c|c|}
\hline Model & $\mathrm{AICc}$ & $\mathrm{w}_{\mathrm{i}}$ & np & Deviance \\
\hline 1. $\mathbf{S o}()=\mathbf{S u}(), \mathbf{p}(), \psi \mathbf{o u}()=\psi \mathbf{u o}()$ & 164.221 & 0.723 & 3 & 64.128 \\
\hline 2. $\mathrm{So}(=\mathrm{Su}(0, \mathrm{p}(), \psi \mathrm{ou}(0 \neq \mathrm{uo} 0$ & 166.441 & 0.245 & 4 & 64.099 \\
\hline 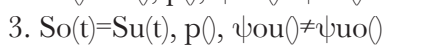 & 173.466 & 0.007 & 9 & 58.781 \\
\hline 4. So $(=\mathrm{Su} 0, \mathrm{p}(), \psi \mathrm{ou}(\mathrm{t}) \neq \psi \mathrm{uo}(\mathrm{t})$ & 174.918 & 0.004 & 13 & 48.797 \\
\hline 5. So $(t)=S u(t), p(t), \psi$ ou ()$\neq \psi$ uo 0 & 175.891 & 0.002 & 13 & 49.770 \\
\hline 6. So $(\mathrm{t})=\mathrm{Su}(\mathrm{t}), \mathrm{p} 0, \psi \mathrm{ou}(\mathrm{t}) \neq \psi \mathrm{uo}(\mathrm{t})$ & 185.868 & 0.000 & 17 & 46.585 \\
\hline
\end{tabular}

AICc, Akaike information criterion corrected; $\mathrm{w}_{\mathrm{i}}$, relative weight of the model; np, number of estimated parameters.

$\hat{\mathrm{C}}$ varied between $60 \%$ and $97 \%$. In most cases, the individual capture probabilities were larger than or equal to 0.4 , which indicated heterogeneity, so model $\mathrm{M}_{\text {th }}$ was chosen. In the other cases with a $\mathrm{CV}\left(\mathrm{p}_{\mathrm{i}}\right)$ smaller than 0.4 , model $M_{t}$ was chosen.

\section{Total seasonal abundance}

According to the previous selection procedure, $\mathbf{M}_{\text {th }}$ and $\mathrm{M}_{\mathrm{t}}$ models were used to estimate the number of identifiable individuals. The correction factor $\hat{c}$ was applied to these estimates in order to obtain an estimate of the total abundance of grey seals in the Molène archipelago in each period (Figure 2).

The total abundance varied from 58 individuals (95\% CI: 48-71) for the period from 18 May to 18 June 1999, to 98 individuals (95\% CI: 75-145) for the period from 16 June to 18 July 1999. For 1999, the abundance increased between May-June and June-July, and then decreased progressively until September when it equalled 65 individuals (95\% CI: 56-77). However, between 16 June 1999 and 30 August 1999, the abundance did not vary much and the confidence intervals overlapped. During the moult, between January and March 2000, the abundance equalled 73 individuals (95\% CI: 49-107).

At the beginning of the survey, the 95\% confidence intervals were large and they then decreased. Generally,

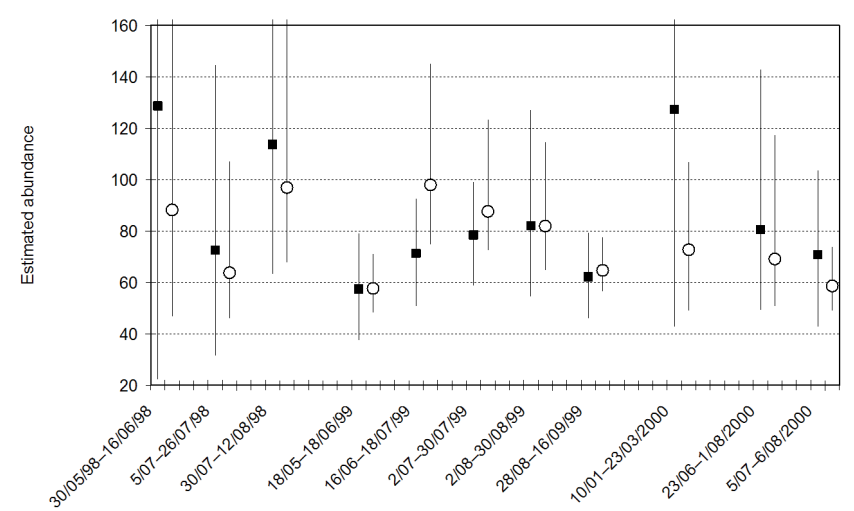

Figure 2. Total grey seal abundance in the Molène archipelago estimated on different periods between March 1998 and August 2000 from capture histories of individuals with a Good pelage pattern (black squares) and individuals with either a Good or a Medium pelage pattern (open circles). they were smaller when the analysis was conducted with the data from the individuals with both Good and Medium pelage patterns.

Abundance estimates conducted from Good or Good and Medium individual recaptures did not vary much. Indeed, estimates obtained from Good and Medium individuals were only $3 \%$ smaller than those obtained from only Good individuals. Therefore, the rest of the analysis was conducted with data from animals of both Good and Medium categories since confidence intervals were smaller and more recapture data were available.

\section{Seasonal site fidelity of male grey seals}

Goodness-of-fit tests showed that the basic model CJS $\Phi_{\mathrm{t}}$ $\mathrm{p}_{\mathrm{t}}$ fitted the data, so multistate models were considered to fit the data too. The deviance profile for males presented two local minima, the first one at 0.03 and the second one at 0.43 .

When probabilities of transition $\Psi$ were time-dependent, a model with a constant survival (Model 5, Table 2) was better than a model where survival varied with time (Model 6, Table 2). When probabilities of transition were constant (Model 4, Table 2), a model with a constant capture probability was preferred (Model 3, Table 2). When we constrained survival probability, we improved the model (Model 2, Table 2). The best model, allowing the assessment of seasonal 'migrations' and site fidelity, was therefore one with constant parameters and probabilities of transition (Model 1, Table 2).

Males displayed a seasonal fidelity of $56 \%$ in any season, and consequently a seasonal emigration and immigration rate of $44 \%$ (Table 3). Moreover, the capture probability of the observable state equalled 0.92 which means that when a male was in the archipelago, it had a $92 \%$ chance of being observed. The survival probability equalled 1.

Table 3. Assessment of males' demographic parameters using the model $S o()=S u(), p(), \psi o u()=\psi u o()$.

\begin{tabular}{lcccc}
\hline Parameter & Estimation & SE & 95\% CI 1.l & 95\% CI u.l \\
\hline 1. So & 1.0000 & $0.335 \times 10^{-5}$ & 0.9944 & 1.0000 \\
2. po & 0.9234 & 0.1099 & 0.3650 & 0.9961 \\
3. pu (fixed) & 0.0000 & 0.0000 & 0.0000 & 0.0000 \\
4. $\psi^{\text {ou }}$ & 0.4359 & 0.0609 & 0.3223 & 0.5566 \\
\hline
\end{tabular}


Table 4. Modelling seasonal occurrence of females during seven periods (summer 98, breeding 98, moult 99, summer 99, breeding 99, moult 2000, summer 2000) using multistate models (o, observable state; $u$, unobservable state). The best model is shown in bold typeface.

\begin{tabular}{|c|c|c|c|c|}
\hline Model & $\mathrm{AICc}$ & $\mathrm{w}_{\mathrm{i}}$ & np & Deviance \\
\hline 1. $\mathbf{S o}()=\mathbf{S u}(), \mathbf{p}(), \psi \mathbf{o u}(\mathbf{t}) \neq \psi \mathbf{u o}(\mathbf{t})$ & 275.884 & 0.945 & 13 & 58.972 \\
\hline 2. $\mathrm{So}()=\mathrm{Su}(), \mathrm{p}(\mathrm{t}), \psi_{\mathrm{ou}}() \neq \psi \mathrm{uo}(0$ & 282.392 & 0.037 & 9 & 72.194 \\
\hline 3. So $(\mathrm{t})=\mathrm{Su}(\mathrm{t}), \mathrm{p} 0, \psi \mathrm{ou}(\mathrm{t}) \neq \psi \mathrm{uo}(\mathrm{t})$ & 284.218 & 0.015 & 17 & 56.866 \\
\hline 4. So $(\mathrm{t})=\mathrm{Su}(\mathrm{t}), \mathrm{p}(\mathrm{t}), \psi_{\mathrm{ou}}(\neq \neq \mathrm{uo} 0$ & 289.576 & 0.001 & 13 & 72.664 \\
\hline 5. So $0=\mathrm{Su} 0, \mathrm{p}(), \psi \mathrm{ou}(\mathrm{t})=\psi \mathrm{uo}(\mathrm{t})$ & 304.573 & 0.000 & 8 & 99.699 \\
\hline 6. So $(\mathrm{t})=\mathrm{Su}(\mathrm{t}), \mathrm{p} 0, \psi \mathrm{ou}(0 \neq \psi \mathrm{uo} 0$ & 326.018 & 0.000 & 9 & 118.820 \\
\hline
\end{tabular}

AICc, Akaike information criterion corrected; $\mathrm{w}_{\mathrm{i}}$, relative weight of the model; np, number of estimated parameters.

\section{Seasonal site fidelity of female grey seals}

Goodness-of-fit tests for females showed a trap-dependence effect (Test 2.CT: $\left.\chi^{2}=10.579, P=0.0317\right)$. Multistate models with an unobservable state take this trap-dependence into account so we assumed our initial model fitted the data.

The value of the Akaike information criterion corrected (AICc) for the first general model $\mathrm{So}(\mathrm{t})=\mathrm{Su}(\mathrm{t}), \mathrm{p}($ ), $\Psi$ ou $(\mathrm{t}) \neq \Psi \mathrm{uo}(\mathrm{t})$ (Model 3, Table 4) was higher than when survival was constrained (Model 1, Table 4). Thus, a constant survival was preferred to a variable one. When the analysis was performed with the second general model $\mathrm{So}(\mathrm{t})=\mathrm{Su}(\mathrm{t})$, $\mathrm{p}(\mathrm{t}), \Psi \mathrm{ou}() \neq \Psi \mathrm{uo})$ (Model 4, Table 4), we found that a constant capture probability did not improve the model. So, a model with a variable capture probability and a constant survival was preferred. Furthermore, when probabilities of transition were set equal (Model 5, Table 4), the model fit decreased. Therefore, the chosen model was the one with constant survival and capture probability, and with variable and different probabilities of transition. No local minimum was underlined in the deviance profile for females.

The results obtained with Model 1 (Table 4) showed that all parameters were estimated (Table 5). The probability of transition between observable and unobservable states from summer 1998 to breeding 1998 was, by definition, not estimable. The capture probability of the observable state was estimated at 1 , which means that when a female was in the archipelago, it was inevitably observed. The survival probability was 0.98. Probabilities of transition from observable to unobservable state (i.e. seasonal emigration) varied among periods. Between summer 1998 and breeding 1998, the probability of transition from observable to unobservable was 0.66 . In other words, $34 \%$ of the females present at Molène in the summer of 1998 were also observed there during the following breeding season of 1998 (seasonal site fidelity). From breeding 1998 to moult 1999, $60 \%$ of the females showed site fidelity. This parameter was 74\% between moult 1999 and summer 1999, 43\% between summer and breeding 1999, 61\% between breeding 1999 and moult 2000, and $85 \%$ between moult and summer 2000. Also, $10 \%$ of the females that were not on the site in the breeding season 1998 were seen during the moult 1999. One hundred per cent of the identified females away from the archipelago in moult 1999 were present in summer 1999, but no female absent during summer 1999 was seen during the following breeding season. Finally, the probability of transition between unobservable and observable states (i.e. seasonal immigration) from breeding 1999 and moult 2000 equalled 49\%, and 80\% between moult and summer 2000 .

Table 5. Assessment of females' demographic parameters using the multistate model $S_{0}()=S u(), p(), \psi o u(t) \neq \psi(u o(t)$. (Italic values represent a non-estimable parameter).

\begin{tabular}{|c|c|c|c|c|}
\hline Parameter & Estimation & $\mathrm{SE}$ & 95\% CI 1.1 & I 95\% CI u.l \\
\hline 1. So & 0.9796 & 0.0125 & 0.9338 & 0.9939 \\
\hline 2. po & 1.0000 & 0.0000 & 0.9236 & 1.0000 \\
\hline 3. pu (fixed) & 0.0000 & 0.0000 & 0.0000 & 0.0000 \\
\hline 4. $\psi^{\text {ou }}$ & 0.6609 & 0.0875 & 0.4756 & 0.8072 \\
\hline 5. $\psi^{\text {ou }}$ & 0.4000 & 0.1549 & 0.1583 & 0.7026 \\
\hline 6. $\psi^{\text {ou }}$ & 0.2639 & 0.1455 & 0.0763 & 0.6088 \\
\hline 7. $\psi^{\text {ou }}$ & 0.5716 & 0.0848 & 0.4035 & 0.7246 \\
\hline 8. $\psi^{\text {ou }}$ & 0.3929 & 0.1280 & 0.1844 & 0.6494 \\
\hline 9. $\psi^{\text {ou }}$ & 0.1489 & 0.1006 & 0.0356 & 0.4532 \\
\hline 10. $\psi^{u o}$ & 0.4501 & 0.000 & $0.200 \times 10^{-14}$ & 1.0000 \\
\hline 11. $\psi^{\text {шо }}$ & 0.1062 & 0.0711 & 0.0266 & 0.3403 \\
\hline 12. $\psi^{\text {ио }}$ & 1.0000 & $0.499 \times 10^{-8}$ & 0.8980 & 1.0000 \\
\hline 13. $\psi^{\text {ио }}$ & $0.167 \times 10^{-13}$ & $0.105 \times 10^{-6}$ & $0.279 \times 10^{-15}$ & $0.139 \times 10^{-6}$ \\
\hline 14. $\psi^{\mathrm{uo}}$ & 0.4895 & 0.1169 & 0.2771 & 0.7058 \\
\hline 15. $\psi^{\text {ио }}$ & 0.7996 & 0.1774 & 0.3131 & 0.9722 \\
\hline
\end{tabular}



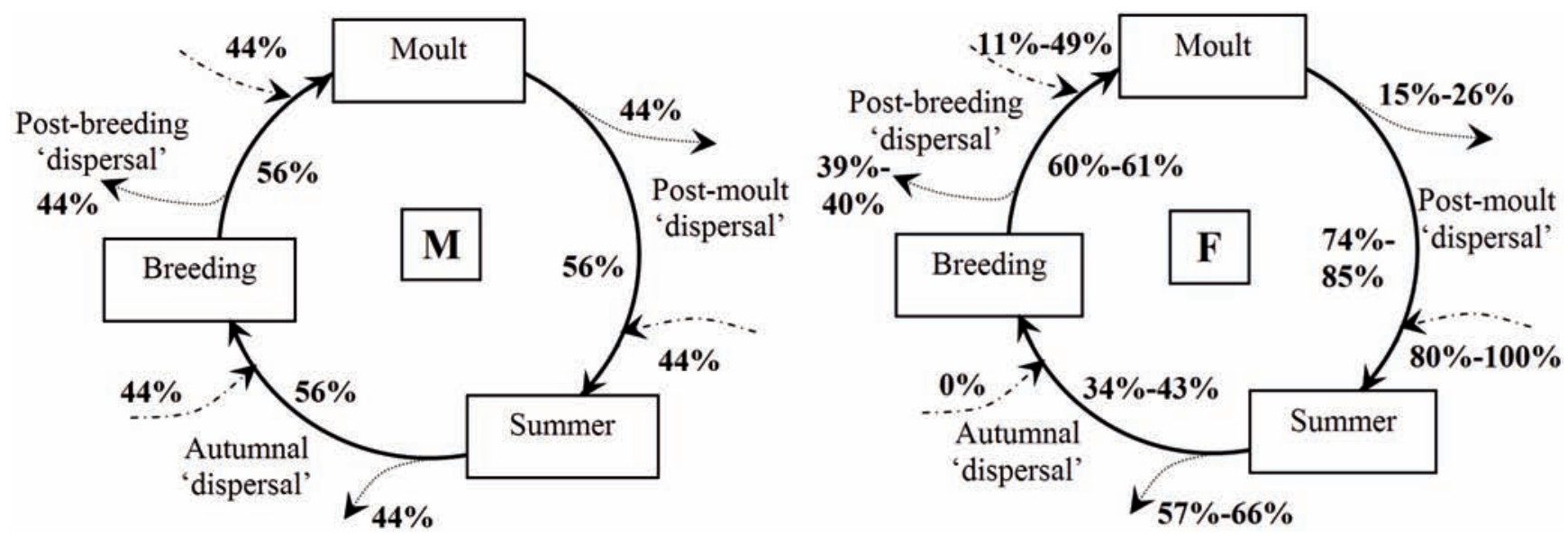

Figure 3. Seasonal patterns of occurrence of grey seal males (M) and females (F) in the Molène archipelago. The black plain arrows indicate their seasonal haul-out site fidelity between three key periods of the annual cycle, the arrows $\rightarrow-\rightarrow$ indicate temporary emigration and the arrows $\rightarrow \rightarrow$ indicate temporary immigration. For females, the two percentages indicate the part of individuals concerned by fidelities or seasonal movements, for 1998-1999 and 1999-2000 respectively.

\section{DISCUSSION}

This is the first estimate of total seal abundance for the Molène archipelago, the main grey seal colony of the French coasts. The use of GMR multistate models allowed us to quantify seasonal site fidelity between key periods of the annual cycle. These results provided basic data needed for the management of the grey seal colony of the Molène archipelago where a project of the Marine Natural Park is underway, and to improve our knowledge about the functioning of peripheral grey seal colonies on the fringes of central populations.

We estimated total grey seal abundance in the archipelago during the summers of 1998, 1999 and 2000 and during the 2000 moulting season (January-March). In summer, the total abundance was estimated between 60 and 100 individuals: around twice the number of seals that were counted instantly on haul-out sites during the same years (Vincent et al., 2005). The large confidence intervals of the estimates in 1998 could be due to the fact that this period corresponded to the early phase of the project when only a small number of individuals had been identified. We therefore suggest that this estimate should be given less confidence than those for the summers of 1999 and 2000.

The abundance estimate obtained during the moulting period was not significantly different from the summer estimates. This contrasts with the higher relative counts made at haul-out sites during the moult (Vincent et al., 2005). We suggest that these high counts do not reflect an increase in the total number of seals in the archipelago during this period but are the result of a behavioural response to the physiological constraints of the moult. Indeed, seals are known to visit haul-out sites more often and stay there longer during the moult (Boily, 1995).

Male grey seals showed a regular pattern in their use of the Molène archipelago: about half of the males present in one season were found during the following one (Figure 3). This confirms that there was no preferential use of the site by males during any period. However, the overall fidelity of individual males to the Molène archipelago is very high (Vincent et al., 2005).
Female grey seals showed significant variations in site fidelity between seasons. It was very high between the moulting period and the summer (74\% in 1999 and 85\% in 2000), lowest between the summer and the breeding periods (34\% in 1998 and 43\% in 2000), and intermediate (around 60\%) between the breeding and the moulting periods. Temporary immigration was highest between the moult and the summer, and lowest between the summer and the breeding season, when it equalled 0 (Figure 3). We found the same pattern of site use from one year to another. Female grey seals use the Molène archipelago preferentially in summer, the period when seals regenerate their energy reserves for the coming breeding season (Hammond \& Fedak, 1994) and tend to use haul-out sites close to their foraging areas (McConnell et al., 1999).

The fidelity values suggest that a significant number of females leave the Molène archipelago to breed elsewhere. Moreover, the small number of females that breed in the Molène archipelago had all been seen there during the summer. Female grey seals show high inter-annual fidelity to their natal site and tend to use this site every year to breed (Pomeroy et al., 2000). This high philopatry could explain the pre-breeding dispersal of females from Molène. It is probable that most of the adult seals using the archipelago were born in British colonies. This could explain the low number of adult seals counted on the Molène archipelago during the breeding period (despite their tendency to haulout more during this period), and the low number of births (Vincent, 2001).

Sixty per cent of the females that were present during the breeding period stayed in the archipelago for the moult. Studies carried out on the central British and Canadian populations show that grey seals disperse after breeding and often moult on a site different from the breeding site (Hammond et al., 1993; Lavigueur \& Hammill, 1993).

The grey seal colony of the Molène archipelago is probably best considered as a local component of the British grey seal metapopulation (Gaggiotti et al., 2002). One of the characteristics of a metapopulation is that the local populations have distinct dynamics (Levins, 1969; Hanski \& Gilpin, 1991). In our case, the breeding population dynamics 
of the colony of the Molène archipelago is different from local British populations. Its relative abundance and pup production remained very low in the 1990s (Härkönen et al., in press), at the same time as pup production in local British populations was increasing by $6 \%$ per annum. However, the rate of increase for seals in the Molène archipelago outside the breeding period (+7\% per year, Vincent et al., 2005) was very similar to that observed at British colonies. Individual grey seals have very large ranges outside the breeding season and individuals from different local populations may overlap extensively at this time. This suggests that a large proportion of the seals using the Molène archipelago outside the breeding period may breed at British colonies.

Our study suggests that monitoring of small colonies provides a unique insight into individual behaviours and metapopulation dynamics. Indeed, the small size of the colony combined with a high photographic effort over time allowed virtually all females and about half of the males to be identified, with a high number of individual recaptures. These data allowed the description of individual patterns of occurrence over the annual cycle, which could not be described in much larger colonies. Small peripheral colonies may also play a role in grey seal metapopulation dynamics. Recently, SMRU (2004) observed a gradual decline in the rate at which pup production has been increasing over the last ten years. Marked regional differences have been reported, but this observation could indicate a saturation of the breeding sites and a density-dependent mechanism in this main local population. Thus, we could expect an increase in dispersal rates of grey seals to the margins of the species distribution range, particularly for the breeding season. In this case, would the Molène archipelago provide adequate habitat for an increasing breeding local population?

We wish to thank Laureline Meynier who greatly helped the elaboration of the photo-identification catalogue, as well as Christelle Puibaraud who worked specifically on the identification of grey seal males. Field work was done with the help of Mathias Rouan and rangers of the Office National de la Chasse et de la Faune Sauvage as well of trainers of the Marine Mammal Laboratory in Oceanopolis. Lex Hiby, Damian Lidgard and Oliver Kiely provided very useful guidelines for photo-identification of the seals. We also wish to thank Eric Poncelet and Hal Whitehead who kindly responded to our requests on CMR analyses. This programme was funded by the Regional Council of Brittany, the French Ministry of Research, the French Ministry of Environment and the EU (Feoga and Feder programmes). Finally, we wish to thank the referee of this paper for useful comments and corrections.

\section{REFERENCES}

Allen, P.J., Amos, W., Pomeroy, P.P. \& Twiss, S.D., 1995. Microsatellite variation in grey seals (Halichoerus grypus) shows evidence of genetic differentiation between two British breeding colonies. Molecular Ecology, 4, 653-662.

Boily, P., 1995. Theoretical heat flux in water and habitat selection of phocid seals and beluga whales during the annual molt. Fournal of Theoretical Biology, 172, 235-244.

Chao, A., Lee, S.-M. \& Jeng, S.-L., 1992. Estimating population size for capture-recapture data when capture probabilities vary by time and individual animal. Biometrics, 48, 201-216.

Choquet, R., Reboulet, A.M., Pradel, R., Gimenez, O. \& Lebreton, J.D., 2003. User's manual for U-CARE. Mimeographed document, CEFE/ CNRS, Montpellier (ftp://ftp.cefe.cnrs-mop.fr/biom/Soft-CR/).
Darroch, J.N., 1958. The multi-recapture census. I. Estimation of a closed population. Biometrika, 45, 343-359.

Gaggiotti, O.E., Jones, F., Lee, W.M., Amos, W., Harwood, J. \& Nichols, R.A., 2002. Patterns of colonization in a metapopulation of grey seals. Nature, London, 416, 424-427.

Hammill, M.O., Stenson, G.B., Myers, R.A. \& Stobo, W.T., 1998. Pup production and population trends of the grey seal (Halichoerus grypus) in the Gulf of St Lawrence. Canadian Fournal of Fisheries and Aquatic Sciences, 55, 423-430.

Hammond, P.S., 1986. Estimating the size of naturally marked whale populations using capture-recapture techniques. Reports of the International Whaling Commission, Special Issue no. 8, 253283.

Hammond, P.S. \& Fedak, M.A., 1994. Grey seals in the North Sea and their interactions with fisheries. Final report to the Ministry of Agriculture, Fisheries and Food under contract MF0503. Sea Mammal Research Unit, St Andrews, UK. 157 pp.

Hammond, P.S., McConnell, B.J. \& Fedak, M.A., 1993. Grey seals off the east coast of Britain: distribution and movements at sea. Symposium of the Zoological Society of London, 66, 211-224.

Hanski, I. \& Gilpin, M., 1991. Metapopulation dynamics: brief history and conceptual domain. Biological Fournal of the Linnean Society, 42, 3-16.

Härkönen, T., Brasseur, S.,Teilmann, J.,Vincent, C., Dietz, R., Abt, K. \& Reijnders, P., in press. Status of grey seals along mainland Europe from the Southwestern Baltic to France. NAMMCO Scientific Publications.

Hewer, H.R. \& Backhouse, K.M., 1959. Field identification of bulls and cows of the grey seal, Halichoerus grypus. Proceedings of the Zoological Society of London, 132, 641-645.

Hiby, L. \& Lovell, P., 1990. Computed aided matching of natural markings: a prototype system for grey seals. Reports of the International Whaling Commission, Special Issue no. 12, 57-61.

Hiby, L., Duck, G., Thompson, D., Hall, A. \& Harwood, J., 1996. Seal stocks in Great Britain. NERC Neres, January 1996, 20-22.

Kendall, W.L. \& Nichols, J.D., 2002. Estimating state-transition probabilities for unobservable states using capture-recapture/ resighting data. Ecology, 83, 3276-3284.

Kiely, O. \& Myers, A.A., 1998. Grey seal (Halichoerus grypus) pup production at the Inishkea island group, Co. Mayo, and Blasket islands, Co. Kerry. Biology and Environment-Proceedings of the Royal Irish Academy, 98, 112-122.

Kiely, O., Lidgard, D., McKibben, M., Connolly, N. \& Baines, M., 2000. Grey seals: status and monitoring in the Irish and Celtic seas. Interreg Report, Cork, Ireland, 76 pp.

Lavigueur, L. \& Hammill, M.O., 1993. Distribution and seasonal movements of grey seals, Halichoerus grypus, born in the Gulf of St Lawrence and Eastern Nova Scotia Shore. Canadian FieldNaturalist, 107, 329-340.

Lebreton, J.-D., Burnham, K.P., Clobert, J. \& Anderson, D.R., 1992. Modeling survival and testing biological hypotheses using marked animals: a unified approach with case studies. Ecological Monographs, 62, 67-118.

Levins, R., 1969. Evolution in changing environments. Princeton, USA: Princeton University Press.

Matthiopoulos, J., Harwood, J. \& Thomas, L., 2005. Metapopulation consequences of site fidelity for colonially breeding mammals and birds. Fournal of Animal Ecology, 74, 716-727.

McConnell, B.J., Fedak, M.A., Lovell, P. \& Hammond, P.S., 1999. Movements and foraging areas of grey seals in the North Sea. Fournal of Applied Ecology, 36, 573-590.

Otis, D.L., Burnham, K.P, White, G.C. \& Anderson, D.R., 1978. Statistical inference from capture data on closed animal populations. Wildlife Monographs, 62, 1-135.

Pomeroy, P.P., Twiss, S.D. \& Redman, P., 2000. Philopatry, site fidelity and local kin associations within grey seal breeding colonies. Ethology, 106, 899-919. 
Sea Mammal Research Unit (SMRU), 2004. Scientific advice on matters related to the management of seal populations: 2004. UK Special Committee on Seals, 99 pp.

Thompson, D., Hammond, P.S., Nicholas, K.S. \& Fedak, M.A., 1991. Movements, diving and foraging behaviour of grey seals. Fournal of Zoology, 224, 223-232.

Thompson, P.M., McConnell, B.J., Tollit, D.J., Mackay, A., Hunter, C. \& Racey, P.A., 1996. Comparative distribution, movements and diet of harbour and grey seals from the Moray Firth, N.E. Scotland. Fournal of Applied Ecology, 33, 1572-1584.

Vincent, G., 2001. Ecological bases for the conservation of the grey seal Halichoerus grypus in the Iroise Sea, France. PhD thesis, University of Brest, France.

Vincent, C., Meynier, L. \& Ridoux, V., 2001. Photo-identification in grey seals: legibility and stability of natural markings. Mammalia, 65, 363-372.
Vincent, C., Fedak, M.A., McConnell, B.J., Meynier, L., SaintJean, C. \& Ridoux, V., 2005. Status and conservation of grey seal, Halichoerus grypus, in France. Biological Conservation, 126, 62-73.

White, G.C., Anderson, D.R., Burnham, K.P. \& Otis, D.L., 1982. Capture-recapture and removal methods for sampling closed populations. Los Alamos, New Mexico, USA: Los Alamos National Laboratory, LA-8787-NERP.

White, G.C. \& Burnham, K.P., 1999. Program MARK: survival estimation from population of marked animals. Bird Study, 46, (Suppl.), S120-138.

Submitted 6 June 2006. Accepted 2 November 2006. 